\title{
Chagas disease: Migration and transmission mechanisms; myths and realities
}

\author{
Angel Ramos-Ligonio, Aracely López-Monteon
}

\section{CHAGAS DISEASE: AN OLD DISEASE}

Chagas disease caused by the protozoan parasite Trypanosoma cruzi, also known as American trypanosomiasis, for more than a century after its discovery, still remains as a very serious problem of public health throughout the Americas [1]. This parasite is usually transmitted to animals and humans through insect vectors that are found primarily in the Americas (especially in rural areas, but today it is no longer a rule), 110 species are found in the Americas and 13 species of no epidemiological significance found in the Old Continent [2]. Chagas disease is a disease characterized by three evolutionary phases concerning of:

(a) the transmission by the insect vector: an acute phase (2-4 months duration), characterized by an inflammatory process by the invasion of the parasite and local response, which together account for the acute manifestations of Chagas disease,

(b) the indeterminate phase (8-10 weeks after the acute phase), this phase occurs whether or not there are clinical manifestations and can take several years or indefinitely. It is characterized by the absence of symptoms. And finally,

Angel Ramos-Ligonio ${ }^{1,2}$, Aracely López-Monteon ${ }^{1,2}$

Affiliations: 'LADISER Inmunología y Biología Molecular, Facultad de Ciencias Químicas, Universidad Veracruzana. Prolongación Oriente 6, No.1009, Col. Rafael Alvarado, 94340, Orizaba, Veracruz, México; ${ }^{2}$ Centro de Investigaciones Biomédicas, Universidad Veracruzana, Luis Castelazo Ayala s/n, Col. Industrial Ánimas, 91190 Xalapa, Veracruz, México.

Corresponding Author: Angel Ramos-Ligonio, PhD, LADISER, Inmunología y Biología Molecular, Facultad de Ciencias Químicas, Universidad Veracruzana, Orizaba, Veracruz, México, Ph \& Fax: 52(272)7240120; Email: angramos@ uv.mx

Received: 08 July 2015

Published: 07 October 2015 (c) the chronic phase $(10-20$ years after initial infection), where chronic cardiomyopathy and visceral megas are the most important changes which accompany this stage [3].

The World Health Organization (WHO) estimates that at least 10 million people worldwide are infected with Chagas disease. An estimation of 8 to 11 million people in Mexico, Central and South America have Chagas disease and most of them do not know they are infected. If these people are not treated, the infection lasts a lifetime and can be life-threatening [4].

\section{TRANSMISSION MECHANISMS: VECTOR BEYOND}

The transmission process of Chagas disease has historically been associated with territorial occupation patterns of human settlements. The presence of the disease in the wild led to the zoonosis, known today as Chagas disease several thousands of years ago, through two forms of territorial occupation that should have occurred in the pre-Columbian populations [5]. In rural areas it can more easily occur vector encounter, pathogens and humans due to the conditions of housing and poverty in these areas [6]. In rural areas of Latin America, the infection is transmitted mainly through the droppings of infected triatomine; the rate of transmission of $T$. cruzi by triatomine depends on several factors inherent in the insect. Among them, the most important is the degree of adaptation to human dwellings. In contrast, the generally free vector cities the flagellate is transmitted primarily through blood transfusion (urbanization of the disease). The importance of this route of transmission is related to social factors such as Chagasic patient's migration from rural areas to cities or underemployment (people who sell their blood for survival need). It interacts with deficient blood banks that ensure good pretransfusion diagnostic; and/or the lack of a diagnosis that is able to identify variants of circulating strains of the parasite. Congenital transmission can be carried out both in rural areas as in cities. However, there are other forms of transmission. Few cases of transmission of $T$. cruzi congenitally are 


\section{EDORIUM Journals}

Edorium J Cell Biol 2015;2:4-7.

Ramos-Ligonio et al.

reported in literature, but it is likely to congenital disease occurs much more frequently than is usually considered and this transmission mechanism is directly related to the prevalence of infection in pregnant women $[7,8]$. Some cases of accidental transmission have been documented in laboratory work, either by inoculation of cultures of infected animals or humans. It should be noted that the transplantation of an organ from a donor Chagasic patient is another mode of transmission. In this context, other forms of contagion have become important; one transmission is orally due to consumption of infected food. The clinical presentation of contracted Chagas disease by oral transmission is different from what is observed with traditional forms of infection. So, after a latency of 5 days post-intakes is expressed with an acute manifestation, as a result of which patients develop severe myocarditis. The scenario is of high mortality; presenting worse prognosis the lower the age is of the patient $[9,10]$. It is difficult to estimate the magnitude of the problem. It is likely to be underdiagnosis of infection by this route because the oral transmission of $T$. cruzi is investigated only when conducted outbreaks in which it has ruled out the possibility of transmission by traditional mechanisms.

\section{CHAGAS DISEASE: THE IMPLICA- TIONS OF MIGRATION}

The impact of this disease is not limited to rural areas of Latin America where transmission occurs through a vector. Migration of large-scale population from rural to urban areas in Latin America and other regions of the world have increased the geographic distribution and changed the epidemiology of Chagas disease. In the United States and in other regions where Chagas disease is present, but not to endemic levels, control strategies should focus on preventing transmission caused by blood transfusions, organ transplants and transmission from mother to baby (congenital). Factors such as economic stagnation and political repression have led to a large influx of people from 17 Latin American countries endemic for Chagas disease to developed countries. As a result of this migration, Chagas disease has become a threat to global health. Chagas disease has been ignored in Japan, as in other developed countries, which brings a lot of stigma and misconceptions against Latin American immigrants. Due to the large number of people in that population without health insurance and that in addition they are facing the difficulty of communication and the lack of preventive measures against infection by $T$. cruzi, which causes some situations of discrimination and also due to globalization and migration, Chagas is a Latin American problem and became a global problem. Currently, there are important foci of infection in Canada, Spain, Italy, Switzerland and Japan [11, 12]. The urbanization of Chagas disease is the result of migration to the big cities of individuals from highly endemic areas.
In the U.S., Chagas disease is to some extent a novelty. The number of cases has grown in recent years and is directly associated with the arrival of migrants who contracted the disease in their countries of origin, most of them, Latin Americans. This problem could get worse if early diagnosis methods that enable the treatment are not established. Though Chagas disease is not cured, reducing blood parasite count improves health prospects notoriously, the existing treatment develops many side effects and research on new drugs from the 60 'and 70' has not made much progress in recent years. In this sense, few have heard of Chagas disease, and currently not even doctors consider when generating a diagnosis. As many infected do not develop the disease and can go decades without noticeable symptoms, detection becomes even more difficult. Thus, Chagas disease has been stigmatized as a disease of migrants [13].

\section{CONSIDERATIONS}

One hundred years after its discovery have made great strides in controlling the disease, but new problems have also appeared. The changes occurring in society and the environment have changed conditions of transmission of the disease for better and for worse. Progress has been much from the point of view of knowledge, building a scientific community and monitoring actions undertaken and goals achieved. However, Chagas disease remains a neglected disease by society and governments, but also, and most alarming is that many of the patients who suffer or are at risk of contracting it remain forgotten. Chagas disease continues to exist more than one hundred years after the first case diagnosis. As is the case with many problems, we must deal with the issue on an integral level so that our actions are all encompassing and do not help only the lucky ones. The risks of disease exist and new and surprising episodes of oral transmission, and the phenomenon of globalization remind us that Chagas disease remains a public health problem... now prevailing worldwide.

Keywords: American trypanosomiasis, Changas disease, Protozoan parasite, Trypanosoma cruzi

\section{How to cite this article}

Ramos-Ligonio A, López-Monteon A. Chagas disease: Migration and transmission mechanisms; myths and realities. Edorium J Cell Biol 2015;2:4-7.

Article ID: 100004Co6AR2015

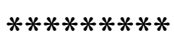

doi:10.5348/Co6-2015-4-ED-2 
$* * * * * * * * *$

\section{Author Contributions}

Angel Ramos-Ligonio - Substantial contribution to conception and design of the experiment, Data acquisition, Analysis and interpretation, Drafting the article, Final approval of the version to be published Aracely López-Monteon - Analysis and interpretation, Drafting the article, Final approval of the version to be published

\section{Guarantor}

The corresponding author is the guarantor of submission.

\section{Conflict of Interest}

Authors declare no conflict of interest.

\section{Copyright}

(C) 2015 Angel Ramos-Ligonio et al. This article is distributed under the terms of Creative Commons Attribution License which permits unrestricted use, distribution and reproduction in any medium provided the original author(s) and original publisher are properly credited. Please see the copyright policy on the journal website for more information.

\section{REFERENCES}

1. Nouvellet P, Cucunubá ZM, Gourbière S. Ecology, evolution and control of Chagas disease: a century of neglected modelling and a promising future. Adv Parasitol 2015 Mar;87:135-91.

2. Ramsey JM, Peterson AT, Carmona-Castro O, et al. Atlas of Mexican Triatominae (Reduviidae: Hemiptera) and vector transmission of Chagas disease. Mem Inst Oswaldo Cruz 2015 May;110(3):339-52.

3. Moncayo A, Ortiz Yanine MI. An update on Chagas disease (human American trypanosomiasis). Ann Trop Med Parasitol 2006 Dec;100(8):663-77.

4. Chagas disease in Latin America: an epidemiological update based on 2010 estimates. Wkly Epidemiol Rec 2015 Feb 6;90(6):33-43.

5. Schofield CJ. Biosystematics of the Triatominae. In: Service MW, editor. Biosystematics of haematophagous insects. Oxford: Clarendon Press; 1988. p. 284-312.

6. Guhl F, Jaramillo C, Vallejo GA, Cárdenas A-Arroyo F, Aufderheide A. Chagas disease and human migration. Mem Inst Oswaldo Cruz 2000 Jul-Aug;95(4):553-5.

7. Buekens $\mathrm{P}$, Almendares O, Carlier Y, et al. Motherto-child transmission of Chagas' disease in North America: why don't we do more? Matern Child Health J 2008 May;12(3):283-6.

8. Sesti-Costa R, Silva JS, Gutierrez FR. Congenital Chagas disease: time to screen pregnant women? Expert Rev Anti Infect Ther 2012 Nov;10(11):127982.
9. de Noya BA, An ecological overview on the factors that drives to Trypanosoma cruzi oral transmission. Acta Trop 2015 Jun 9. pii: Sooo1-706X(15)30025-5.

10. Benchimol Barbosa PR. The oral transmission of Chagas' disease: an acute form of infection responsible for regional outbreaks. Int J Cardiol 2006 Sep 10;112(1):132-3.

11. Coura JR, Viñas PA, Junqueira AC. Ecoepidemiology, short history and control of Chagas disease in the endemic countries and the new challenge for nonendemic countries. Mem Inst Oswaldo Cruz 2014 Nov;109(7):856-62.

12. Imai K, Maeda $\mathrm{T}$, Sayama $\mathrm{Y}$, et al. Chronic Chagas disease with advanced cardiac complications in Japan: Case report and literature review. Parasitol Int 2015 Oct;64(5):240-2.

13. Bern C, Kjos S, Yabsley MJ, Montgomery SP. Trypanosoma cruzi and Chagas' Disease in the United States. Clin Microbiol Rev 2011 Oct;24(4):655-81.

\section{SUGGESTED READING}

- Barreto-de-Albuquerque J, Silva-Dos-Santos D, Pérez AR, Berbert LR, Santana-van-Vliet Ed, et. al. Trypanosoma cruzi Infection through the Oral Route Promotes a Severe Infection in Mice: New Disease Form from an Old Infection? PLoS Negl Trop Dis. 2015; 9(6):eooo3849. doi: 10.1371/journal. pntd.0003849.

- Coura JR, Dias JC. Epidemiology, control and surveillance of Chagas disease 100 years after its discovery. Mem Inst Oswaldo Cruz. 2009; 104(4):3140.

- $\quad$ Steverding D. The history of Chagas disease. Parasit Vectors. 2014 Jul 10;7:317.

- Viotti R, Vigliano C, Armenti A. Nothing goes on forever Chagas disease. Rev Esp Cardiol. 2009; 62(11):1332-3. 


\section{EDORiUM Journals}

Edorium J Cell Biol 2015;2:4-7.

http://www.edoriumjournalofcellbiology.com

Access full text article on other devices

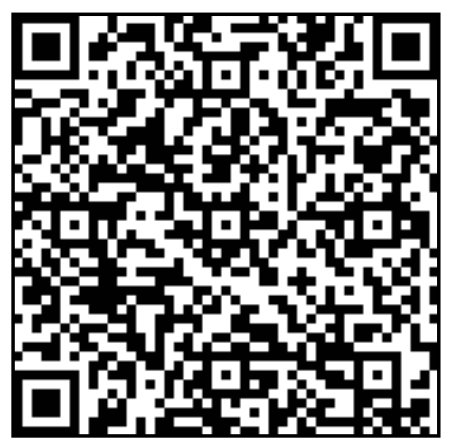

Access PDF of article on other devices

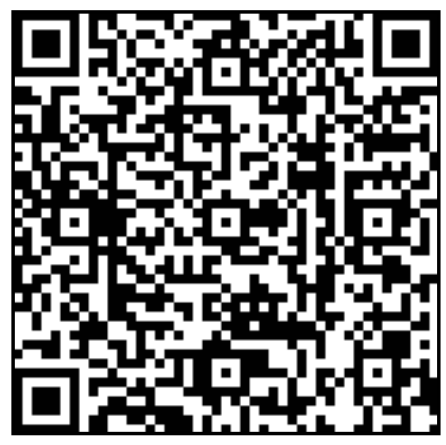

